\section{Shear-wave elastography for the assessment of testicular involvement of hematologic malignancies in children and young adults: a feasibility study}

\author{
Seok Young Koh', Seunghyun Lee ${ }^{1,2}$, Seul Bi Lee ${ }^{1}$, Yeon Jin Cho ${ }^{1}$, Young Hun Choi ${ }^{1,2}$, \\ Jung-Eun Cheon ${ }^{1,2,3}$, Woo Sun Kim ${ }^{1,2,3}$ \\ ${ }^{1}$ Department of Radiology, Seoul National University Hospital, Seoul; ${ }^{2}$ Department of \\ Radiology, Seoul National University College of Medicine, Seoul; ${ }^{3}$ Institute of Radiation \\ Medicine, Seoul National University Medical Research Center, Seoul, Korea
}

Purpose: This study aimed to assess the feasibility of shear-wave elastography (SWE) for assessing the testicular involvement of hematologic malignancies in children and young adults. Methods: Eight patients (mean age, 11.0 years; range, 0.8 to 20 years) with biopsy-confirmed testicular involvement of hematologic malignancy between January 2018 and December 2020 were retrospectively evaluated. Multiparametric ultrasound examinations, including grayscale, color Doppler ultrasonography (CDUS), and SWE, were performed. Stiffness was measured in the involved testicular area and contralateral normal parenchyma. If there was bilateral testicular involvement, the stiffness of the involved area and the adjacent normal echoic parenchyma was measured on one testis. The Mann-Whitney $U$ test was used to compare stiffness values.

Results: On grayscale, the testicular lesions were noted as a solitary mass in one patient, multiple lesions in four patients, and diffuse involvement in three patients. On CDUS and SWE, all patients demonstrated increased vascularity, and the stiffness of the involved area was higher than the values of normal parenchyma (the involved area vs. normal parenchyma, 11.6 $\mathrm{KPa}$ [3.9-20.2 $\mathrm{kPa}$ ] vs. $2.9 \mathrm{kPa}[1.1-3.7 \mathrm{kPa}], \mathrm{P}=0.003)$. The ratio of stiffness between the involved area and normal parenchyma was 3.4, ranging from 1.9 to 5.1. One patient showed decreased stiffness on follow-up SWE after treatment (affected testis vs. normal testis: initial, 13.8 vs. $3.2 \mathrm{kPa} ; 1$ year later, 2.2 vs. $2.4 \mathrm{kPa}$ ).

Conclusion: Increased testicular stiffness on SWE in children and young adults with hematologic malignancies suggests the possibility of testicular involvement.

Keywords: Testis; Leukemia; Ultrasonography; Elastography; Child

Key points: Increased testicular stiffness on shear-wave elastography (SWE) in children and young adults with hematologic malignancies suggests the possibility of testicular involvement. SWE evaluation for testicular involvement of hematologic malignancies is a feasible, noninvasive imaging modality that can help diagnose testicular involvement and evaluate the treatment response.

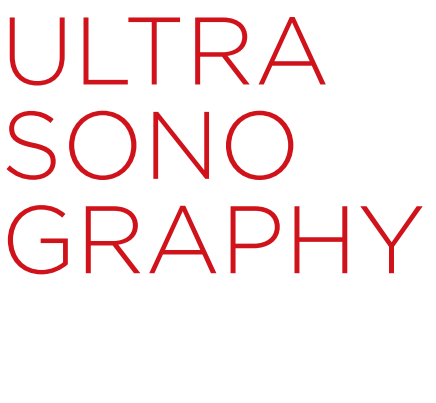

ORIGINAL ARTICLE

https://doi.org/10.14366/usg.21072 pISSN: 2288-5919 - elSSN: 2288-5943

Ultrasonography 2022;41:325-334

Received: March 26, 2021

Revised: August 31, 2021

Accepted: September 6, 2021

Correspondence to:

Seunghyun Lee, MD, Department of Radiology, Seoul National University Hospital, 101 Daehak-ro, Jongno-gu, Seoul 03080, Korea

Tel. +82-2-2072-3608

Fax. $+82-2-747-5781$

E-mail: seunghyun.lee.22@gmail.com

This is an Open Access article distributed under the terms of the Creative Commons Attribution NonCommercial License (http://creativecommons.org/ licenses/by-nc/4.0/) which permits unrestricted noncommercial use, distribution, and reproduction in any medium, provided the original work is properly cited.

Copyright (C) 2022 Korean Society of Ultrasound in Medicine (KSUM)

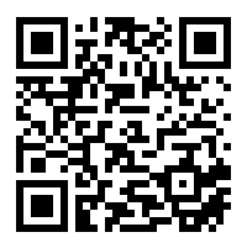

How to cite this article:

Koh SY, Lee S, Lee SB, Cho YJ, Choi YH, Cheon JE, et al. Shear-wave elastography for the assessment of testicular involvement of hematologic malignancies in children and young adults: a feasibility study. Ultrasonography. 2022 Apr;41(2):325-334. 


\section{Introduction}

Hematologic malignancies are the most common category of childhood malignancies, and testicular involvement has been reported in approximately $2 \%$ of boys upon the initial diagnosis of leukemia [1]. Although testicular involvement is uncommon, an early diagnosis of testicular involvement in children and young adults with hematologic malignancies is essential, as it has been associated with poor outcomes. Testicular involvement is also important to assess in cases of relapse of a hematologic malignancy, as well as in the initial diagnosis [1-3].

A testicular ultrasound examination is performed to identify testicular involvement of a hematologic malignancy if asymmetric testicular enlargement is observed on the physical examination of a patient suspected of having a hematologic malignancy [4]. Either hypoechoic mass formation or parenchymal enlargement in the testis can be observed on grayscale ultrasound images. Color Doppler ultrasonography (CDUS) also shows increased vascularity inside the involved lesion of the testis $[4,5]$. However, when diffuse testicular involvement occurs instead of focal mass-forming lesions in patients with hematologic malignancies, the subtle changes in grayscale and CDUS findings might make it challenging to diagnose testicular involvement and to monitor treatment response [6].

In contrast, testicular ultrasound elastography, which was recently introduced, can provide additional quantitative and qualitative information about tissue stiffness to evaluate testicular involvement of hematologic malignancies in children and young adults. Testicular ultrasound elastography has been studied in pediatric patients with diverse conditions such as undescended testis, microlithiasis, hydroceles, torsion, and varicocele [7-12]. A few studies have focused on differentiating germ cell tumors, which are the most common testicular tumor in adult patients, from benign testicular tumors, and have shown increased testicular stiffness values in the malignant region $[5,13]$. However, there is a lack of literature regarding shear-wave elastography (SWE) for identifying testicular involvement of hematologic malignancies in pediatric patients $[5,14,15]$.

This study aimed to assess the feasibility and usefulness of SWE in the diagnosis of testicular involvement of hematologic malignancies in children and young adult patients.

\section{Materials and Methods}

\section{Compliance with Ethical Standards}

Institutional review board approval of Seoul National University Hospital was obtained for this retrospective study. The requirement for informed consent was waived as the study was retrospective (IRB
No. 2012-024-1178).

\section{Patient Population}

This study retrospectively reviewed eight children and young adult patients with biopsy-confirmed testicular hematologic malignancy, who were identified by searching the institution's picture archiving and communication system (Infinitt, Infinitt Healthcare, Seoul, Korea) database between January 2018 and December 2020. Hematologic malignancy patients with suspected testicular involvement were referred for testis ultrasonography and percutaneous biopsies to assess their histopathological condition. The testicular biopsies were performed in the testis on the involved side, and if the bilateral testes were involved, the testis with the larger mass or that was easier to approach was biopsied. The diagnosis of hematologic malignancy was confirmed by bone marrow biopsy before testicular biopsy in all eight patients.

\section{Ultrasound Examinations}

All ultrasound evaluations were performed by a pediatric radiologist with experience in SWE (S.L., with 8 years of experience). Multiparametric ultrasound examinations, including grayscale, CDUS, and SWE, were performed with a broadband high-frequency linear array transducer (SL15-4) using an Aixplorer machine (SuperSonic Imagine SA, Aix-en-Provence, France).

The number of lesions was recorded for diffuse, multiple nodular, and solitary lesions. The testis volume $\left(\mathrm{mm}^{3}\right)$ was calculated as $0.523 \times$ length $(\mathrm{mm}) \times$ height $(\mathrm{mm}) \times$ width $(\mathrm{mm})$. The ratio of testis volume between the affected and normal testis was calculated. The grayscale appearance was divided into hyperechoic, isoechoic, hypoechoic, or heterogeneous echogenicity compared to the normal testis parenchyma. The vascularity observed on CDUS images was classified as normal, increased central vascularity, increased peripheral vascularity, and central/peripheral mixed vascularity.

The median stiffness and the ratio of stiffness between the involved area and normal testis on SWE images were evaluated. The stiffness was measured on the involved testicular area and contralateral normal parenchyma using a region of interest. If there was bilateral testicular involvement, the stiffness of the involved area and adjacent normal echoic parenchyma was measured on the testis on one side. At least 10 consecutive measurements were performed, and if the normalized value divided by the interquartile range/median value from a total of 10 measurements showed a variation of $30 \%$ or more, the stiffness measurement and the image quality were regarded as insufficient owing to the high variability of the stiffness value. Only one patient underwent a follow-up evaluation by SWE and percutaneous biopsy 1 year after the initial ultrasound examination. 


\section{Statistical Analyses}

Statistical analyses were performed using SPSS version 25.0 for Windows (IBM Corp., Armonk, NY, USA). The Mann-Whitney U test was used for non-parametric evaluation of continuous variables. Statistical significance was set at a P-value $<0.05$.

\section{Results}

Eight patients (mean age, 11.0 years; range, 0.8 to 20 years) with testicular hematologic malignancies were included in the present study. A 20-year-old patient was included because he was diagnosed with acute lymphoblastic leukemia at 3 years old and had a relapse at 20 years old. Six patients presented with testicular asymmetry without pain, one with painful testicular asymmetric swelling, and one with no symptoms. Three patients had relapsed leukemia, and one of them had a history of testicular involvement. Percutaneous biopsy-confirmed testicular involvement of hematologic malignancy in all patients. Six patients were diagnosed with acute lymphoblastic leukemia, one with anaplastic large cell lymphoma, and one with acute myeloid leukemia (Table 1).

In grayscale images, the ratio of testis volume between the affected and normal testis was 2.2 (range, 1.3 to 6.9 ), and a variable pattern was found in association with testicular hematologic malignancy (Table 2). There was no side predilection: the right side was involved in three patients, the left side in two patients, and bilateral involvement was observed in three patients. The lesions were noted as a solitary mass in one patient, multiple lesions in four patients (Fig. 1A) and diffuse involvement of the testis in three patients (Figs. 2A, 3A). The lesions were hypoechoic in five patients and heterogeneous in three patients. On CDUS, all showed increased vascularity compared to either the adjacent normal testicular parenchyma or contralateral normal testis (Figs. 1A, 2A, $3 B$ ). In most cases (seven of eight), increased linear vascularity was observed in the central portion of the tumors. In the remaining

Table 1. Clinical characteristics of testicular leukemic infiltrations

\begin{tabular}{|c|c|c|c|c|}
\hline ID & Age (year) & Testicular enlargement & Initial involvement & Diagnosis \\
\hline 1 & 20 & Unilateral & Testis, bone marrow & Lymphoblastic leukemia (relapsed \\
\hline 2 & 14 & Bilateral & $\begin{array}{r}\text { Testis, bone marrow, and others (CNS, spleen, liver, pancreas, kidney, } \\
\text { colon, thymus) }\end{array}$ & B-lymphoblastic leukemia \\
\hline 3 & 13 & No & Testis, bone marrow, and others (spleen, lung, lymph nodes) & Anaplastic large cell lymphoma \\
\hline 4 & 11 & Unilateral & Testis, bone marrow, and others (CNS, spleen) & $\begin{array}{l}\text { B-lymphoblastic leukemia } \\
\text { (relapsed) }\end{array}$ \\
\hline 5 & 10 & Unilateral & Testis, bone marrow, and others (lymph nodes, liver, peritoneum, kidney) & B-lymphoblastic leukemia \\
\hline 6 & 13 & Unilateral & Testis, bone marrow & Lymphoblastic leukemia \\
\hline 7 & 6 & Unilateral & Testis, bone marrow & $\begin{array}{l}\text { B-lymphoblastic leukemia } \\
\text { (relapsed) }\end{array}$ \\
\hline 8 & 0.8 & Bilateral & Testis, bone marrow & Acute myeloid leukemia \\
\hline
\end{tabular}

CNS, central nervous system.

Table 2. Multiparametric ultrasound imaging characteristics

\begin{tabular}{|c|c|c|c|c|c|c|c|c|c|c|c|}
\hline \multirow[b]{2}{*}{ ID } & \multirow[b]{2}{*}{ Side } & \multicolumn{5}{|c|}{ Grayscale } & \multicolumn{2}{|c|}{ CDUS } & \multicolumn{3}{|c|}{ SWE } \\
\hline & & $\begin{array}{l}\text { Affected testis } \\
\left(\mathrm{mm}^{3}\right)\end{array}$ & $\begin{array}{c}\text { Other testis } \\
\left(\mathrm{mm}^{3}\right)\end{array}$ & Ratio & Pattern & Echogenicity & Vascularity & Pattern & $\begin{array}{c}\text { Affected } \\
\text { testis }(\mathrm{kPa})\end{array}$ & $\begin{array}{c}\text { Other testis } \\
(\mathrm{kPa})\end{array}$ & Ratio \\
\hline 1 & Right & 46.5 & 14.2 & 3.3 & Diffuse & Heterogeneous & $\uparrow$ & Central & 3.9 & 1.1 & 3.4 \\
\hline 2 & Bilateral & 12.4 & 8.4 & 1.5 & Multiple & Hypoechoic & $\uparrow$ & Central & 7.0 & 3.7 & 1.9 \\
\hline 3 & Right & 3.1 & 2.0 & 1.6 & Solitary & Hypoechoic & $\uparrow$ & Peripheral & NA & NA & NA \\
\hline 4 & Right & 4.3 & 1.2 & 3.6 & Multiple & Hypoechoic & $\uparrow$ & Central & 15.6 & 3.1 & 5.1 \\
\hline 5 & Left & 7.0 & 1.0 & 6.9 & Multiple & Heterogeneous & $\uparrow$ & Central & 13.8 & 3.2 & 4.4 \\
\hline 6 & Left & 5.6 & 4.2 & 1.3 & Diffuse & Heterogeneous & $\uparrow$ & Central & 7.2 & 3.3 & 2.2 \\
\hline 7 & Bilateral & 3.0 & 1.1 & 2.7 & Diffuse & Hypoechoic & $\uparrow$ & Central & 20.2 & NA & NA \\
\hline 8 & Bilateral & 5.9 & 3.6 & 1.6 & Diffuse & Hypoechoic & $\uparrow$ & Central & 13.3 & NA & NA \\
\hline
\end{tabular}

CDUS, color Doppler ultrasonography; SWE, shear-wave elastography; NA, not applicable; $\uparrow$, increase. 


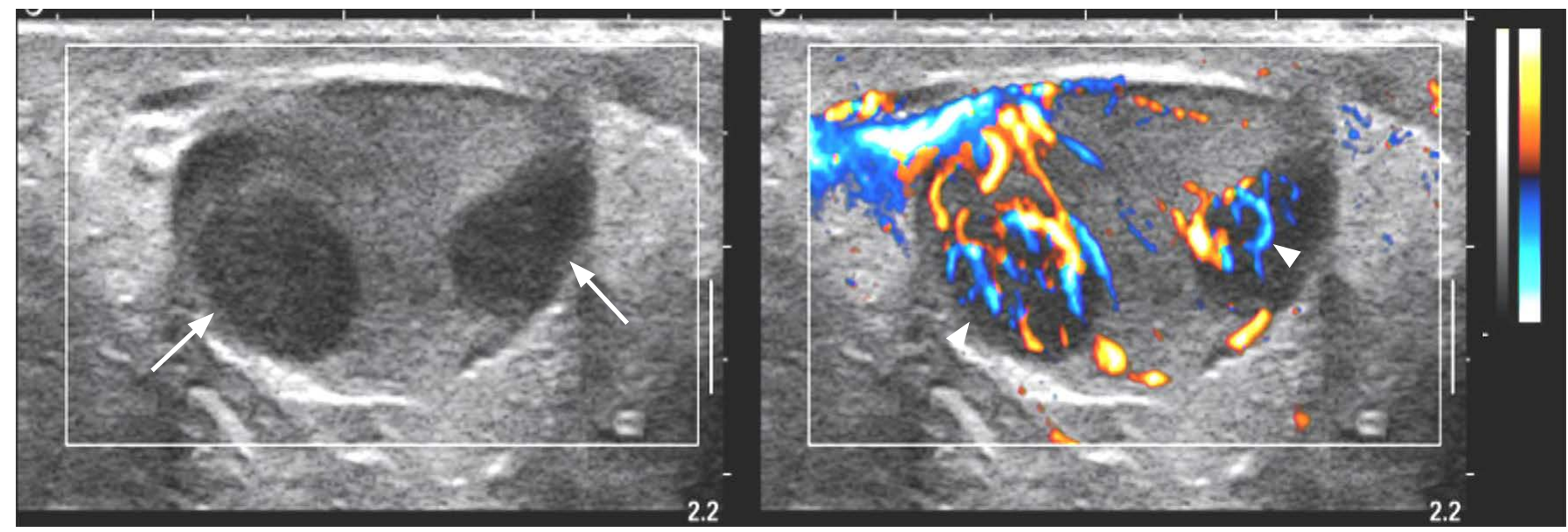

A

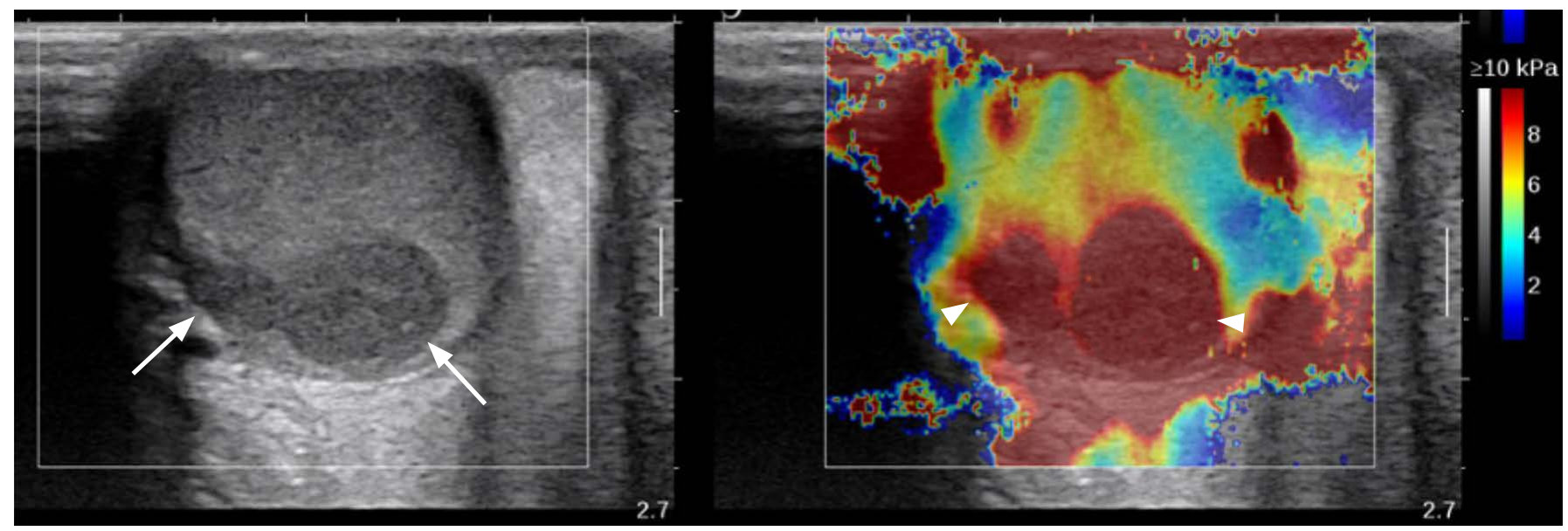

B

Fig. 1. An 11-year-old boy with histologically proven B-lymphoblastic leukemia of the right testis (patient No. 4).

A. Grayscale image (left) of the right testis shows multifocal hypoechoic nodules (arrows) and color Doppler ultrasonography (CDUS) (right) shows increased linear vascularity in the central portion of the hypoechoic lesions (arrowheads). B. Shear-wave elastography (SWE) (right) shows that the hypoechoic nodules (arrows) had increased stiffness (arrowheads) of $15.6 \mathrm{kPa}$, and the ratio between the nodule stiffness and normal testicular parenchyma stiffness was 5.1.

patient, peripheral dominant vascularity was observed.

On SWE, seven patients were evaluated for the stiffness of the involved testis, and among them, five were evaluated for the stiffness of the normal testis. In all five patients with values for the normal parenchymal stiffness as well as that of the involved testis, the stiffness of the involved area was higher than the values of the normal parenchyma (the involved area vs. normal parenchyma: 11.6 $\mathrm{kPa}$ [range, 3.9 to $20.2 \mathrm{kPa}$ ] vs. $2.9 \mathrm{kPa}$ [range, 1.1 to $3.7 \mathrm{kPa}$, $\mathrm{P}=0.003$ ) (Figs. 1B, 2B, 3C, D). The ratio of stiffness between the involved area and normal parenchyma was 3.4 , ranging from 1.9 to 5.1.

One patient underwent a follow-up ultrasound examination with SWE after 1 year (Fig. 3E). The volume of the affected testis measured on grayscale ultrasonography had decreased, but a size discrepancy remained (affected testis vs. normal testis: initial, 7.0 $\mathrm{mm}^{3}$ vs. $1.0 \mathrm{~mm}^{3}$; 1 year later, $3.2 \mathrm{~mm}^{3}$ vs. $2.1 \mathrm{~mm}^{3}$ ); however, the stiffness was dramatically reduced (affected testis vs. normal testis: initial, 13.8 vs. $3.2 \mathrm{kPa}$; 1 year later, 2.2 vs. $2.4 \mathrm{kPa}$ ). The pathology findings of the percutaneous biopsy of the involved testis only showed interstitial fibrosis, and atypical lymphocytes were not found.

\section{Discussion}

Our study assessed whether SWE could be a feasible tool for the noninvasive diagnosis of testicular involvement when asymmetric 


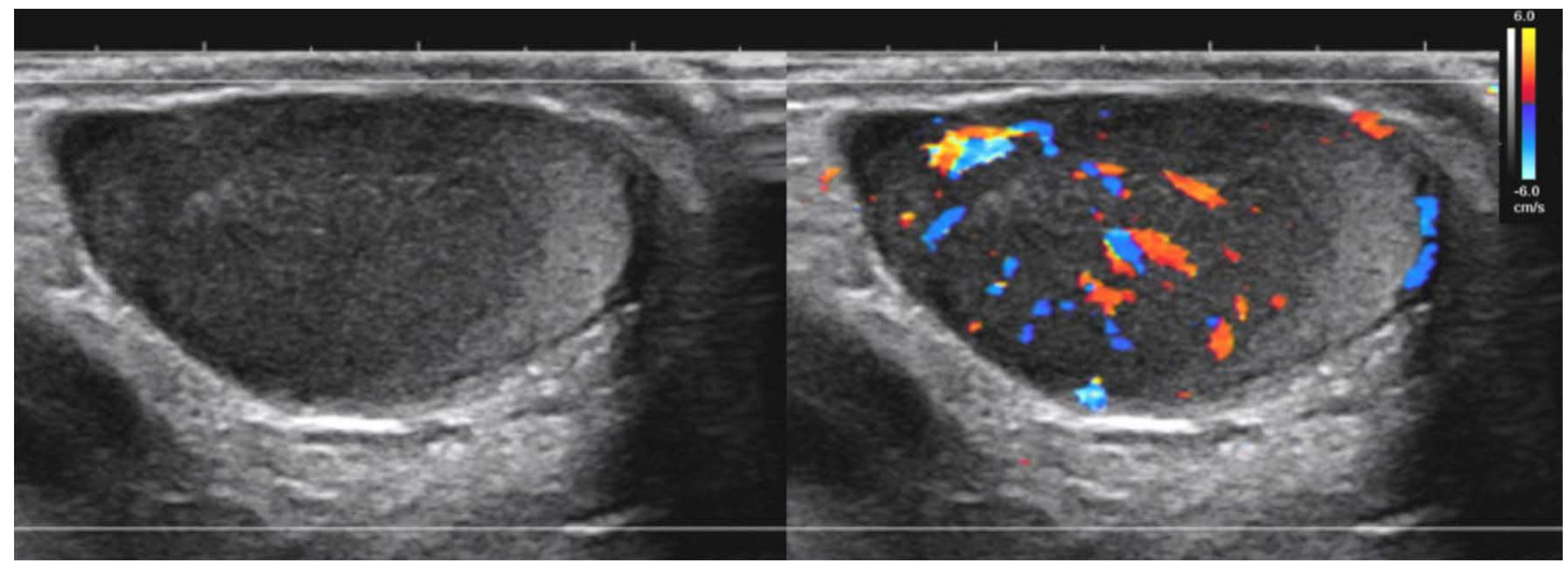

A

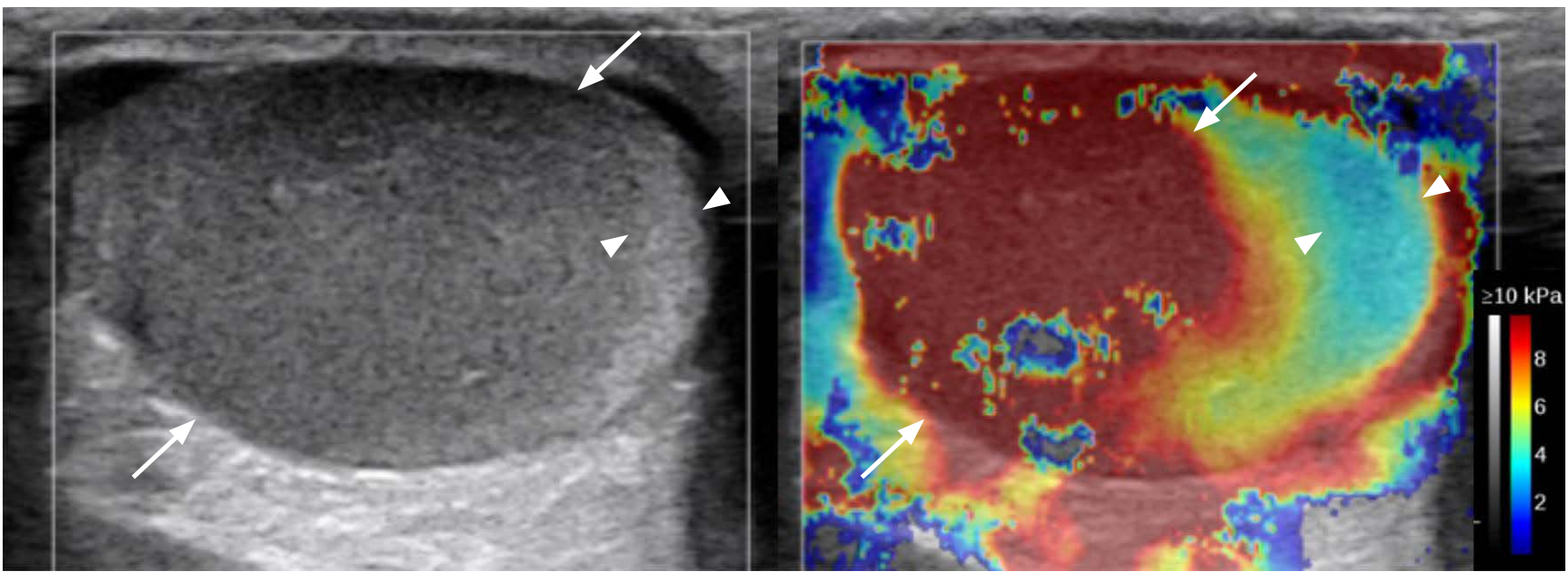

B

Fig. 2. A 6-year-old boy with histologically proven B-lymphoblastic leukemia of the bilateral testis (patient No. 7).

A. Grayscale image (left) shows diffuse hypoechogenicity of the left testis and color Doppler ultrasonography (CDUS) (right) shows increased central vascularity in the hypoechoic lesion. B. Shear-wave elastography (SWE) of the right testis shows increased stiffness in the hypoechoic lesion (arrows) compared with the normal echoic area (arrowheads). The median stiffness of the hypoechoic lesion was $20.2 \mathrm{kPa}$.

enlargement of the testes is observed in pediatric hematologic malignancy patients. Half of the patients did not show focal lesions, but demonstrated diffuse testicular enlargement with increased vascularity on conventional grayscale and CDUS images. The stiffness of the affected testis observed on SWE images was significantly higher than that in the normal parenchyma. In addition, objective and quantitative follow-up evaluations of the affected testis could assist in monitoring disease progression.

The most common pediatric hematologic malignancy is acute lymphoblastic leukemia. Overt testicular involvement is more common in pediatric patients than in adults at diagnosis despite the rarity of this entity, and it has the risk of testicular relapse due to the blood-testis barrier, even if systemic chemotherapy is administered [16]. Testicular involvement often presents as leukemic cell infiltrations in the testis with a bone marrow abnormality in pediatric patients, whereas adult patients older than 60 years present with primary lymphoma such as diffuse large B-cell lymphoma in the testis [17]. However, regardless of the patient's age, pathologically, in testicular lymphoma/leukemia, atypical lymphoid cells diffusely infiltrate the interstitial tissue surrounding the seminiferous tubules without destruction [6].

The infiltration and aggregation of abnormal lymphoid lesions can lead to hypo-echogenicity and hypervascularity because the density of tumor cells and vessels is greater than that of normal 


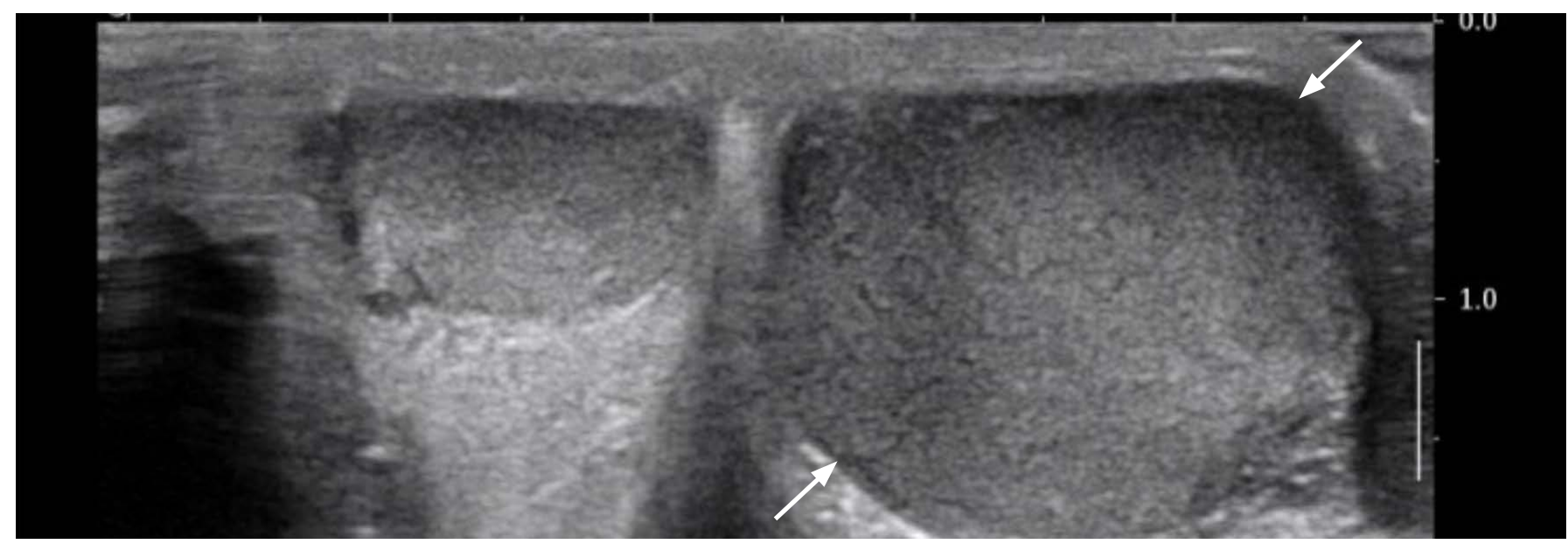

A

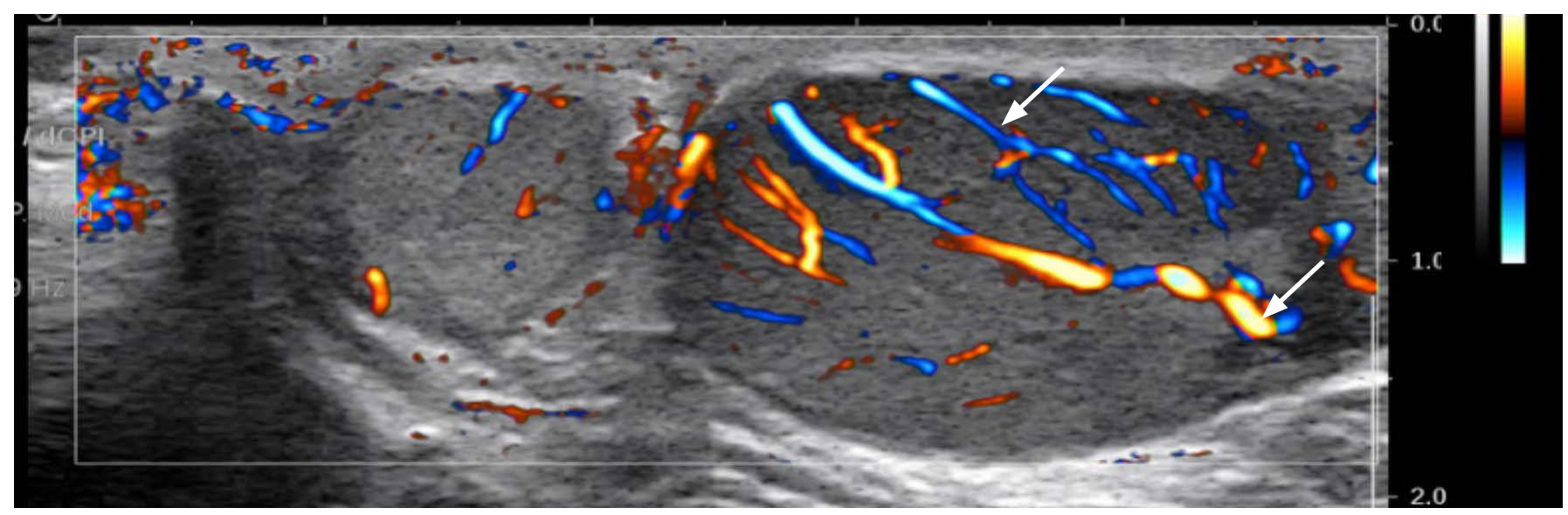

B

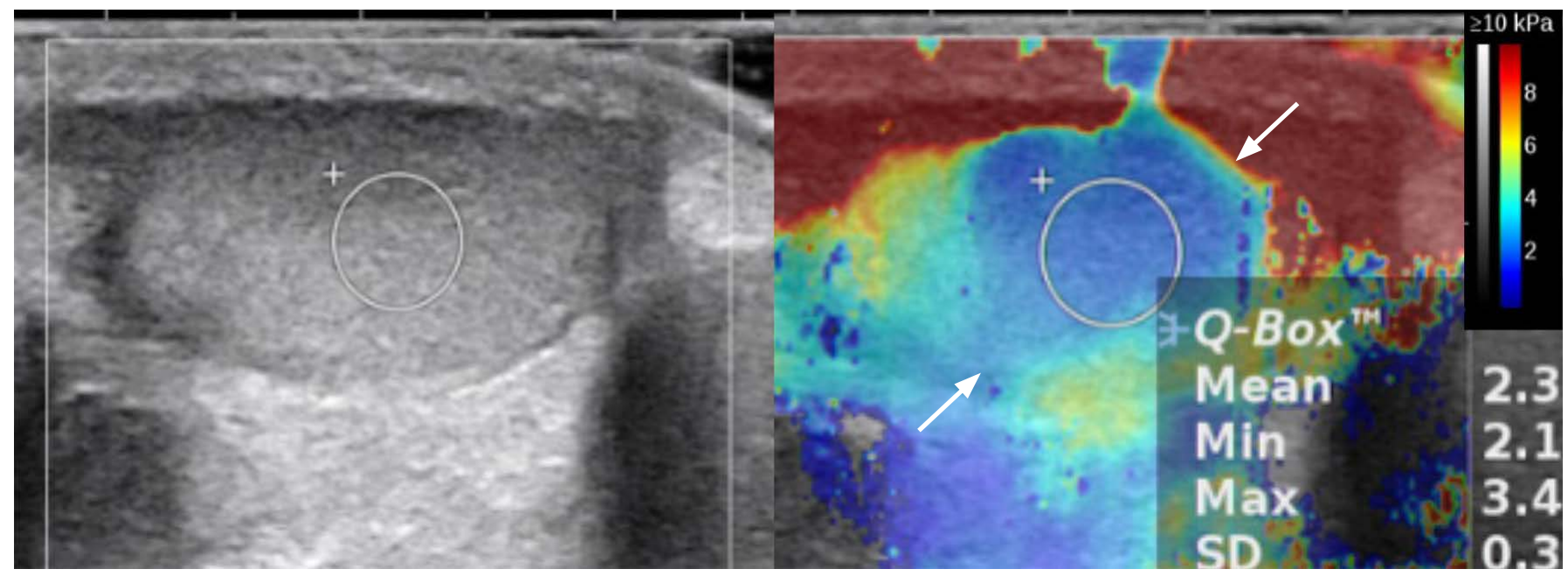

C

Fig. 3. A 10-year-old boy with histologically proven B-lymphoblastic leukemia of the left testis (patient No. 5).

A. Grayscale image of the left testis shows diffuse enlargement and multiple ill-defined heterogeneous echoic lesions (arrows). B. Color Doppler ultrasonography shows increased linear vascularity in the left testis (arrows). C. Shear-wave elastography (SWE) of the right normal testis shows a stiffness of $2.3 \mathrm{kPa}$ (arrows) (median, $3.2 \mathrm{kPa}$ ). 


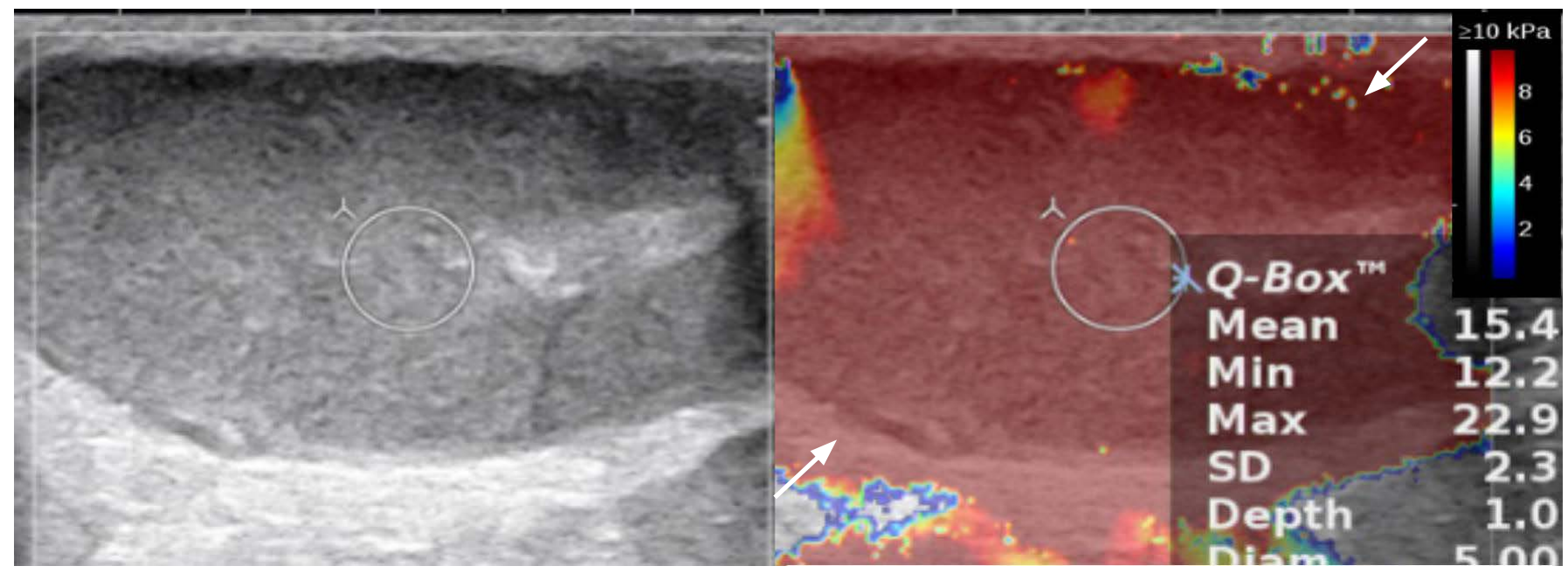

D

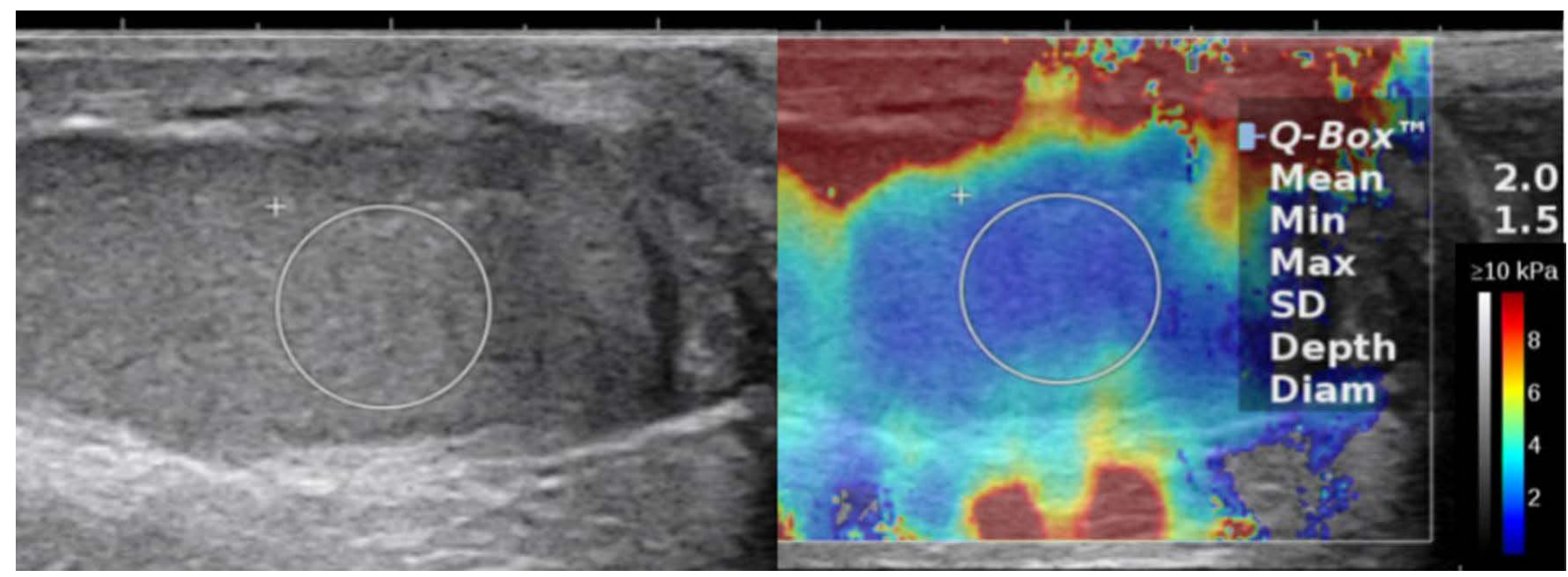

E

Fig. 3. D. SWE of the heterogeneous echoic portion in the left testis shows increased stiffness (arrows) of $15.4 \mathrm{kPa}$ (median, $13.8 \mathrm{kPa}$ ), and the ratio between the nodule stiffness of the left testis and the right normal testicular parenchyma stiffness was 4.4. E. Follow-up SWE after 1 year reveals no change in the asymmetrically enlarged involved testis; however, the stiffness was dramatically reduced (2.0 kPa).

testicular tissue [15]. Therefore, grayscale ultrasound imaging findings of testicular hematologic malignancies in pediatric and adult patients are commonly observed as hypoechoic single/multiple or diffuse involvement, combined with increased vascularity on CDUS images [4]. In a previous study of 43 adult patients with testicular lymphomas, testicular lymphomas presented as hypoechoic lesions of the testis, either focal or diffuse, on grayscale images and increased vascularity on CDUS images [18]. In another study of eight patients with testicular lymphoma, involvement also appeared as a solitary nodule (25\%), diffuse infiltration of the entire testis $(38 \%)$, and multiple lesions (38\%), showing increased vascularity compared to normal testicular parenchyma [14]. Diffuse lymphomatous infiltration leads to maintenance of the normal ovoid testicular shape; however, hypoechoic striations radiating peripherally from the mediastinum are observed. Previous studies have reported that the vascular architecture is preserved owing to diffuse infiltration, which results in increased vascularity of non-branching linear patterns on CDUS $[6,14]$. The grayscale ultrasound images of the cases in the present study showed findings consistent with those of these previous studies, and most patients showed increased central vascularity on CDUS, except one, who showed increased peripheral vascularity. However, although abnormalities were noted on grayscale and Doppler images in all patients in previous studies, it might make it challenging regarding some cases, especially those in which there was diffuse testicular infiltration by lymphoma or leukemia. 
Recently, the elastography technique in testicular ultrasonography has been studied with the goal of establishing the normal range of stiffness values in adults and pediatric patients and differentiating benign and malignant testicular lesions in adult patients. The normal testicular stiffness value was reported to be $2.4 \mathrm{kPa}$ in 62 normal adults with a mean age of 37.9 years and $3.3-3.8 \mathrm{kPa}$ in $32 \mathrm{normal}$ adults with a mean age of 51.0 years $[19,20]$. One study reported that pediatric patients (mean age, 23.5 months) showed a normal range of 3.1-3.9 $\mathrm{kPa}$ [21]. In terms of testicular malignancies, Rocher et al. [5] reported that malignant testis tumors had higher median stiffness values than benign Leydig cell tumors (17.73 kPa [12.01-25.05 kPa] vs. $6.05 \mathrm{kPa}$ [4.20-9.85 kPa]). The median stiffness ratio of the lesion to the normal parenchyma was also higher in malignant tumors than in benign Leydig cell tumors (12.87 vs. 2.65). Dikici et al. [13] demonstrated that the mean stiffness value of seminoma was higher than normal testicular parenchyma $(10.6 \pm 3.9 \mathrm{kPa}$ vs. $4.4 \pm 3.9 \mathrm{kPa})$. Therefore, SWE might be helpful for the identification of malignant testicular lesions in adult patients with testicular masses. Their study raised awareness regarding the usefulness of testicular SWE, mentioning that SWE combined with CDUS and grayscale ultrasound significantly improved the characterization of testicular masses. However, there is a lack of studies regarding SWE in the assessment of testicular involvement of hematologic malignancies in children, and the diagnostic performance of testicular SWE has not been extensively studied. The present study showed that the stiffness of the involved area was also higher than the normal parenchyma (11.6 kPa vs. $2.9 \mathrm{kPa}$ ), which is a similar trend to those reported in the previous studies about malignant testicular lesions in adults. This phenomenon might be due to the higher density of lymphoid tumor cells and vessels than in normal testicular tissue despite the lack of evaluation of accurate histologic changes. In addition, the cases in this study included diffuse involvement of the testis and nodular mass-forming lesions in the testis. Therefore, SWE might help diagnose and monitor challenging cases, especially those with diffuse enlargement due to hematologic abnormal cell infiltration by lymphoma or leukemia.

The present study focused on hematologic malignancies in children and young adults; all cases showed increased stiffness of the involved testis on SWE similar to that in adult patients. It is difficult to explain the exact reason for the high SWE values in testicular malignancies, as several factors such as the mitotic index or fibrosis of the capsule can theoretically affect stiffness measurements in the testis [5]. One hypothesis relates to the histologic background of hematologic malignancies in the testes, as these cases could show interstitial infiltration of leukemic cells [22]. Regarding the high SWE in testicular varicocele, thickened tubular basement membranes and increased deposition of interstitial fibrous tissue with germ cell atrophy were possible explanations noted in previous studies $[23,24]$, and it was assumed that these findings might lead to increased stiffness on SWE [25]. Similarly, interstitial leukemic cell infiltration, secondary atrophy of the seminiferous tubules, and increased blood capillaries in testes with hematologic malignancy involvement may lead to increased stiffness on SWE. Another interesting finding was that one patient showed decreased stiffness on follow-up SWE. Subsequent testicular biopsy revealed the absence of tumor tissue, even with remaining testicular enlargement and low-echoic lesions, suggesting the possibility that SWE might help with the treatment response evaluation as well as the initial diagnosis.

The limitations of the present study were that there was only a single follow-up ultrasound SWE examination, and it was not possible to demonstrate a direct correlation between the stiffness values and the histopathological parameters. To the best of the authors' knowledge, there is no apparent pathophysiological description of the sonographic features of SWE in testes with hematologic malignancy involvement. However, this study shows the feasibility and potential role of SWE in diagnosing testicular involvement of hematologic malignancy. Therefore, it could be valuable for further investigations to analyze the stiffness and histologic features in a large population study despite the rarity of testicular involvement of hematologic malignancies in childhood. Another limitation was a small number of patients and heterogeneous disease distribution. Although SWE has been used to diagnose testicular lesions in recent years, cases of testicular involvement in hematologic malignancies in children and especially biopsy-confirmed cases of SWE imaging are rare. Therefore, this study could be the basis for further research regarding the usefulness of SWE to assess testicular involvement in patients with hematologic malignancies.

In conclusion, increased testicular stiffness on SWE in children and young adults with hematologic malignancies suggests the possibility of testicular involvement. Therefore, SWE evaluation of testicular involvement in hematologic malignancies is a feasible noninvasive imaging modality that can help diagnose testicular hematologic malignancies and evaluate the treatment response.

ORCID: Seok Young Koh: https://orcid.org/0000-0003-1853-3166; Seunghyun Lee: https://orcid.org/0000-0003-1858-0640; Seul Bi Lee: https://orcid.org/0000-00025163-3911; Yeon Jin Cho: https://orcid.org/0000-0001-9820-3030; Young Hun Choi: https://orcid.org/0000-0002-1842-9062; Jung-Eun Cheon: https://orcid.org/00000003-1479-2064; Woo Sun Kim: https://orcid.org/0000-0003-2184-1311 


\section{Author Contributions}

Conceptualization: Koh SY, Lee S. Data acquisition: Koh SY, Lee S, Lee SB, Cho YJ, Choi YH, Cheon JE, Kim WS. Data analysis or interpretation: Koh SY, Lee S, Lee SB, Cho YJ, Choi YH, Cheon JE, Kim WS. Drafting of the manuscript: Koh SY, Lee S, Lee SB, Cho YJ, Choi $Y H$, Cheon JE. Critical revision of the manuscript: Koh SY, Lee $S$, Lee SB, Cho YJ, Choi YH, Cheon JE, Kim WS. Approval of the final version of the manuscript: all authors.

\section{Conflict of Interest}

Jung-Eun Cheon serves as Editor for the Ultrasonography, but has no role in the decision to publish this article. All remaining authors have declared no conflicts of interest.

\section{Acknowledgments}

This work was supported by a National Research Foundation of Korea (NRF) grant funded by the Korean government (MSIT) (No. 2020R1C1C1008716) and by grant no 04-2020-0760 from the SNUH Research Fund.

\section{References}

1. Hijiya N, Liu W, Sandlund JT, Jeha S, Razzouk BI, Ribeiro RC, et al. Overt testicular disease at diagnosis of childhood acute lymphoblastic leukemia: lack of therapeutic role of local irradiation. Leukemia 2005;19:1399-1403.

2. Gajjar A, Ribeiro RC, Mahmoud HH, Sandlund JT, Liu Q, Furman WL, et al. Overt testicular disease at diagnosis is associated with high risk features and a poor prognosis in patients with childhood acute lymphoblastic leukemia. Cancer 1996;78:2437-2442.

3. Barredo JC, Hastings C, Lu X, Devidas M, Chen Y, Armstrong D, et al. Isolated late testicular relapse of B-cell acute lymphoblastic leukemia treated with intensive systemic chemotherapy and response-based testicular radiation: a Children's Oncology Group study. Pediatr Blood Cancer 2018;65:e26928.

4. De Zordo T, Stronegger D, Pallwein-Prettner L, Harvey CJ, Pinggera G, Jaschke $W$, et al. Multiparametric ultrasonography of the testicles. Nat Rev Urol 2013;10:135-148.

5. Rocher L, Criton A, Gennisson JL, Creze M, Albiges L, Ferlicot S, et al. Characterization of testicular masses in adults: performance of combined quantitative shear wave elastography and conventional ultrasound. Ultrasound Med Biol 2019;45:720-731.

6. Mazzu D, Jeffrey RB Jr, Ralls PW. Lymphoma and leukemia involving the testicles: findings on gray-scale and color Doppler sonography. AJR Am J Roentgenol 1995;164:645-647.

7. Ucar AK, Alis D, Samanci C, Aslan M, Habibi HA, Dikici AS, et al. A preliminary study of shear wave elastography for the evaluation of unilateral palpable undescended testes. Eur J Radiol 2017;86:248251.

8. Bayramoglu Z, Kandemirli SG, Comert RG, Akpinar YE, Caliskan E, Yilmaz $R$, et al. Shear wave elastography evaluation in pediatric testicular microlithiasis: a comparative study. J Med Ultrason (2001) 2018:45:281-286.

9. Kocaoglu C, Durmaz MS, Sivri M. Shear wave elastography evaluation of testes with non-communicating hydrocele in infants and toddlers: a preliminary study. J Pediatr Urol 2018;14:445.

10. Zeng B, Chen F, Qiu S, Luo Y, Zhu Z, Chen R, et al. Application of quasistatic ultrasound elastography for examination of scrotal lesions. J Ultrasound Med 2016;35:253-261.

11. Sun Z, Xie M, Xiang F, Song Y, Yu C, Zhang Y, et al. Utility of realtime shear wave elastography in the assessment of testicular torsion. PLoS One 2015;10:e0138523.

12. Ryu YJ, Choi YH, Kim JY, Cheon JE, Kim WS, Kim IO, et al. A preliminary study of shear-wave elastography for the evaluation of varicocele in adolescents and young adults. Ultrasonography 2022:41:131-139.

13. Dikici AS, Er ME, Alis D, Samanci C, Ustabasioglu FE, Demirdag $C$, et al. Is there any difference between seminomas and nonseminomatous germ cell tumors on shear wave elastography? a preliminary study. J Ultrasound Med 2016;35:2575-2580.

14. Kachramanoglou C, Rafailidis V, Philippidou M, Bertolotto M, Huang DY, Deganello A, et al. Multiparametric sonography of hematologic malignancies of the testis: grayscale, color Doppler, and contrastenhanced ultrasound and strain elastographic appearances with histologic correlation. J Ultrasound Med 2017;36:409-420.

15. Fang $C$, Huang DY, Sidhu PS. Elastography of focal testicular lesions: current concepts and utility. Ultrasonography 2019;38:302-310.

16. Nguyen $\mathrm{HT}$, Terao MA, Green DM, Pui $\mathrm{CH}$, Inaba $\mathrm{H}$. Testicular involvement of acute lymphoblastic leukemia in children and adolescents: diagnosis, biology, and management. Cancer 2021;127:3067-3081.

17. Miedler JD, MacLennan GT. Primary testicular lymphoma. J Urol 2007; 178:2645.

18. Bertolotto M, Derchi LE, Secil M, Dogra V, Sidhu PS, Clements R, et al. Grayscale and color Doppler features of testicular lymphoma. J Ultrasound Med 2015;34:1139-1145.

19. Rocher L, Criton A, Gennisson JL, Izard V, Ferlicot S, Tanter M, et al. Testicular shear wave elastography in normal and infertile men: a prospective study on 601 patients. Ultrasound Med Biol 2017:43:782-789.

20. Marcon J, Trottmann M, Rubenthaler J, D'Anastasi M, Stief CG, Reiser MF, et al. Three-dimensional vs. two-dimensional shear-wave elastography of the testes: preliminary study on a healthy collective. Clin Hemorheol Microcirc 2016;64:447-456.

21. Shin HJ, Yoon H, Lee YS, Kim MJ, Han SW, Roh YH, et al. Normal changes and ranges of pediatric testicular volume and shear wave 
elasticity. Ultrasound Med Biol 2019;45:1638-1643.

22. Wakasa $\mathrm{H}$, Amano S. Histopathology on testicular involvement of leukemia with an emphasis on lymphatics. Tohoku J Exp Med 1977;123:147-159.

23. Abdelrahim F, Mostafa A, Hamdy A, Mabrouk M, el-Kholy M, Hassan 0 . Testicular morphology and function in varicocele patients: pre-operative and post-operative histopathology. Br J Urol 1993;72:643-647.

24. Agger P, Johnsen SG. Quantitative evaluation of testicular biopsies in varicocele. Fertil Steril 1978;29:52-57.

25. Turna 0 , Aybar MD. Testicular stiffness in varicocele: evaluation with shear wave elastography. Ultrasonography 2020;39:350-355. 